\title{
Clinical Study \\ Endothelial Cell Markers in Patients with Pseudoexfoliation Syndrome
}

\author{
Joanna Stafiej, ${ }^{1}$ Grażyna Malukiewicz, ${ }^{1}$ Hanna Lesiewska-Junk, ${ }^{1}$ \\ Danuta Rość, ${ }^{2}$ and Karolina Kaźmierczak ${ }^{1}$ \\ ${ }^{1}$ Department of Ophthalmology, Ludwik Rydygier's Collegium Medicum, The Nicolaus Copernicus University, \\ Curie-Skłodowskiej 9, 85-094 Bydgoszcz, Poland \\ ${ }^{2}$ Department of Pathophysiology, Ludwik Rydygier's Collegium Medicum, The Nicolaus Copernicus University, \\ Curie-Skłodowskiej 9, 85-094 Bydgoszcz, Poland
}

Correspondence should be addressed to Hanna Lesiewska-Junk, hanjot@op.pl

Received 18 December 2011; Accepted 12 January 2012

Academic Editors: Z. Bashshur and N. Ishizaka

Copyright ( $(2012$ Joanna Stafiej et al. This is an open access article distributed under the Creative Commons Attribution License, which permits unrestricted use, distribution, and reproduction in any medium, provided the original work is properly cited.

\begin{abstract}
The aim of the study was the assessment of the von Willebrand antigen (vWF Ag), E-selectin, and P-selectin concentration in blood plasma of patients with pseudoexfoliation syndrome (PEX). The group studied comprised 30 patients with PEX, aged from 50 to 86 years (mean 73, SD \pm 8 years). Patients with cardiovascular and cerebrovascular diseases, diabetes mellitus, infectious disease, cancer, renal or liver insufficiency, connective tissue disease, current smoking, and hormone, antiplatelet, hypolipidemic, antioxidant, or antihypertensive drug therapy were excluded from the study. Each subject underwent a complete ophthalmological examination. Venous blood samples from the cubital vein were taken into sodium citrate solution. VWF Ag, sP-selectin, and sE-selectin concentration were determined by a commercially available enzyme-linked immunosorbent assay (MedSystems, Diagnostica Stago/Roche, R\&D). Concentrations of vWF Ag, soluble E-selectin, and soluble P-selectin in blood plasma in the study group were compared with the levels in blood plasma in the control group. No significant differences were found between the groups. Our results indicate that there might be no correlation between PEX and such endothelial cell markers as vWF Ag, sPselectin, and sE-selectin concentrations. Since the study size is limited, further investigations to confirm that there is no association between endothelial dysfunction in PEX and risk of future cardiovascular disease are necessary.
\end{abstract}

\section{Introduction}

Pseudoexfoliation syndrome (PEX) is a common age-related fibrillinopathy of unknown cause, primarily manifested in eyes by the accumulation of microscopic granular amyloidlike protein fibers. Originally, PEX was thought to be limited to the anterior segment of the eye, recent studies have indicated, however, that pseudoexfoliative material may be present in blood vessels; impaired endothelial function can be observed [1-3]. Since endothelial dysfunction is an independent predictor of future cardiovascular events, its presence in PEX syndrome patients might suggest an increased vascular risk [4-6]. Connection between inflammatory markers and markers of endothelial dysfunction favours the hypothesis that also inflammation could be involved in the etiopathogenesis of vascular disease [7]. An established marker of endothelial damage or dysfunction is von Wille- brand factor (vWF) which is considered as biomarker in etiologic pathway of arteriosclerotic vascular disease [8]. The selectin family of cellular adhesion molecules (CAMs) plays a prominent role in immune/inflammatory responses $[9,10]$. The aim of our study is to determine concentrations of biomarkers which may, according to the literature [11], precede the symptoms of vascular diseases, in patients with PEX and no other ocular nor systemic diseases. The present study is, to the best of our knowledge, the first one to evaluate vWF Ag and sCAMs levels in serum of patients with pseudoexfoliation syndrome.

\section{Patients and Methods}

Among 143, consecutive patients with PEX 113 were excluded based on general or ocular exclusion criteria. This 
prospective study involved 30 patients (18 females and 12 males) and 37 control subjects (25 females and 12 males) without PEX nor any history of systemic disease.

The study has been approved by the Medical Ethics Committee of Collegium Medicum Bydgoszcz Nicolaus Copernicus University in Torun. Written informed consent was obtained from all study participants. A detailed medical history was collected from all subjects. Patients with cardiovascular diseases (defined as a history of myocardial infarction, angina pectoris, heart failure, left ventricular dysfunction, and peripheral arterial disease), diabetes mellitus, hypertension, cerebrovascular disease, infectious disease, cancer, renal or liver insufficiency, connective tissue disease, Parkinson's disease, current smoking, and hormone, antiplatelet, hypolipidemic, antioxidant or antihypertensive drug therapy were excluded from the study. Ocular exclusion criteria included a history of other than glaucoma neuropathies, anterior or posterior segment inflammation, chorioretinal degeneration, and retinal vascular diseases.

Each subject underwent a complete ophthalmological examination including slit lamp biomicroscopy after pupil dilation. Venous blood samples from the cubital vein were taken into sodium citrate solution $(9: 1)$. All venepunctures were performed using minimal venostasis, after $15 \mathrm{~min}$ in the recumbent position. In order to obtain low-platelet plasma, the blood samples were centrifuged at $+4^{\circ} \mathrm{C}$ for 20 minutes with the speed of 3000 rotations per minute. The citrate plasma obtained in the procedure was divided into portions (approx. $200 \mu \mathrm{L}$ ) placed in Eppendorf tubes. The material was then frozen in the temperature of $-70^{\circ} \mathrm{C}$ until the study was being conducted. Von WF concentration, E-selectin and P-selectin levels were determined by a commercially available enzyme-linked immunosorbent assay using kits produced by Bender MedSystems, Diagnostica Stago/Roche, R\&D.

Statistical Analysis. The Mann Whitney $U$ test was used to compare patient and control groups for possible differences in vWF concentration and E-selectin and P-selectin levels.

\section{Results}

The group studied comprised of $60 \%$ women and $40 \%$ men and similar rate was observed in the control one (68\% versus $32 \%)$. There was no significant difference between study and control group in regards of gender.

Mean age in the studied group was 73 years $(S D=8)$ and in control one $-57(\mathrm{SD}=10)$.

The level of vWF Ag was not markedly elevated in patients with PEX, as compared to the controls $(P=0.5748)$. No significant differences were found in sE-selectin $(P=$ $0.9666)$ and sP-selectin $(P=0.0519)$ levels between the patients with PEX syndrome and the control group. Detailed results are presented in Table 1 .

\section{Discussion}

The etiology and pathophysiology of PEX still remain unexplained. Increased prevalence of the disease in certain
TABLE 1: Endothelial cell markers in blood plasma of patients with PEX and controls.

\begin{tabular}{|c|c|c|}
\hline Parameter & $\begin{array}{l}\text { Study group (median, } \\
\text { Quartile1 \& Quartile3) }\end{array}$ & $\begin{array}{c}\text { Control group } \\
\text { (median, quartile1, } \\
\text { quartile3) }\end{array}$ \\
\hline $\begin{array}{l}\text { von Willebrandt } \\
\text { antigen }(\%)\end{array}$ & $\begin{array}{c}67,77 \\
\mathrm{Q} 1=53,59 \\
\mathrm{Q} 3=80,89\end{array}$ & $\begin{array}{c}66,36 \\
\text { Q1 }=59,55 \\
\text { Q3 }=81,82\end{array}$ \\
\hline $\begin{array}{l}\text { sE-selectin } \\
(\mathrm{ng} / \mathrm{mL})\end{array}$ & $\begin{array}{c}40,27 \\
\mathrm{Q} 1=27,94 \\
\mathrm{Q} 3=54,64\end{array}$ & $\begin{array}{c}40,94 \\
\mathrm{Q} 1=33,16 \\
\mathrm{Q} 3=60,12\end{array}$ \\
\hline $\begin{array}{l}\text { sP-selectin } \\
(\mathrm{ng} / \mathrm{mL})\end{array}$ & $\begin{array}{c}86,85 \\
\mathrm{Q} 1=71,16 \\
\mathrm{Q} 3=110,72\end{array}$ & $\begin{array}{c}100,97 \\
Q 1=70,35 \\
Q 3=146,19\end{array}$ \\
\hline
\end{tabular}

populations and observed familial aggregation are compatible with PEX being a complex genetic disorder. A strong association between two nonsynonymous single nucleotide polymorphisms (SNPs) in the LOXL1 gene and PEX was detected [12-16]. Lysyl oxidase (LOX) belongs to a family of extracellular copper-requiring enzymes that facilitate cross-linking of collagen and elastane through oxidative deamination of lysine or hydroxylysine side chains and play a key role in collagen and elastane stabilizing. For over 10 years, PEX has been considered a systemic disease. There are also suggestions that this disease is linked to disorders impairing blood vessels [2]. Many authors have observed a connection between pseudoexfoliation syndrome and cardiovascular or cerebrovascular diseases $[4,11,17-19]$. Yet, there are no reports concerning the difference between PEX which is accompanied with other morbidities and that without such comorbidities.

Allingham et al. indicated in their study that pseudoexfoliation syndrome was strongly associated with the presence of glaucoma, but was associated with neither AMD nor systemic diseases [20].

Biomarkers of endothelial injury such as vWF, E-selectin, and P-selectin have been implicated in the development and progression of vascular diseases [7, 11, 21-27]. So far there are no reports on correlation between LOXL1 activation and endothelial dysfunction, vascular injury nor vWF/selectins. Elevated levels of vWF, sE-selectin, and sPselectin may develop as a result of endothelial damage mediated by hypertension. That's why patients displaying such diseases were excluded from the study. The lack of statistically significant differences in vWF Ag, sE-selectin, and sP-selectin levels between the group of PEX patients and the control group in our study suggests that there is no correlation between PEX and endothelial dysfunction. Thus, nonincreased level of the selectins in patients with PEX may indicate the lack of connection between this syndrome and vascular diseases. Other authors' results also support such a conclusion [2830]. However, it is possible that other factors, such as thrombogenicity, are enhanced in PEX and this would increase the risk of cardiovascular event. Although PEX is thought to be related with cardiovascular diseases, our research casts doubt on the existence of such a link. Similarly, Tarkkanen 
in his review concluded that there is no evidence that pseudoexfoliation syndrome or pseudoexfoliation glaucoma are related to increased mortality from cardiovascular diseases [31]. Nevertheless, the underlying pathogenesis of PEX might be multifactorial. Because hitherto, a clearcut association of PEX with asystemic diseases is yet to be shown, further large-scale, randomized clinical studies are required.

\section{Conclusion}

Our results indicate that there might be no correlation between PEX and vWF Ag, sP-selectin, and sE-selectin endothelial cell markers concentrations. The study size is limited therefore further investigations are required to confirm the lack of association between endothelial dysfunction and PEX.

\section{References}

[1] B. W. Streeten, Z. Y. Li, R. N. Wallace, R. C. Eagle, and A. A. Keshgegian, "Pseudoexfoliative fibrillopathy in visceral organs of a patient with pseudoexfoliation syndrome," Archives of Ophthalmology, vol. 110, no. 12, pp. 1757-1762, 1992.

[2] S. Schumacher, U. Schlötzer-Schrehardt, P. Martus, W. Lang, and G. Naumann, "Pseudoexfoliation syndrome and aneurysms of the abdominal aorta," The Lancet, vol. 357, no. 9253, pp. 359-360, 2001.

[3] P. T. Atalar, E. Atalar, H. Kilic et al., "Impaired systemic endothelial function in patients with pseudoexfoliation syndrome," International Heart Journal, vol. 47, no. 1, pp. 77-84, 2006.

[4] P. Mitchell, J. J. Wang, and W. Smith, "Association of pseudoexfoliation syndrome with increased vascular risk," American Journal of Ophthalmology, vol. 124, no. 5, pp. 685-687, 1997.

[5] T. Neunteufl, S. Heher, R. Katzenschlager et al., "Late prognostic value of flow-mediated dilation in the brachial artery of patients with chest pain," American Journal of Cardiology, vol. 86, no. 2, pp. 207-210, 2000.

[6] V. Schächinger, M. B. Britten, and A. M. Zeiher, "Prognostic impact of coronary vasodilator dysfunction on adverse longterm outcome of coronary heart disease," Circulation, vol. 101, no. 16, pp. 1899-1906, 2000.

[7] M. K. Jezovnik and P. Poredos, "Idiopathic venous thrombosis is related to systemic inflammatory response and to increased levels of circulating markers of endothelial dysfunction," International Angiology, vol. 29, no. 3, pp. 226-231, 2010.

[8] M. Khaleghi, L. A. Singletary, V. Kondragunta et al., "Haemostatic markers are associated with measures of vascular disease in adults with hypertension," Journal of Human Hypertension, vol. 23, no. 8, pp. 530-537, 2009.

[9] M. Kelly, J. M. Hwang, and P. Kubes, "Modulating leukocyte recruitment in inflammation," Journal of Allergy and Clinical Immunology, vol. 120, no. 1, pp. 3-10, 2007.

[10] O. Eschen, J. H. Christensen, C. Dethlefsen, and E. B. Schmidt, "Cellular adhesion molecules in healthy subjects: short term variations and relations to flow mediated dilation," Biomarker Insights, vol. 2008, no. 3, pp. 57-62, 2008.

[11] R. Ross, "Atherosclerosis-an inflammatory diseas," The New England Journal of Medicine, vol. 340, pp. 115-126, 1999.

[12] G. Thorleifsson, K. P. Magnusson, P. Sulem et al., "Common sequence variants in the LOXL1 gene confer susceptibility to exfoliation glaucoma," Science, vol. 317, no. 5843, pp. 1397 1400, 2007.
[13] J. A. Aragon-Martin, R. Ritch, J. Liebmann et al., "Evaluation of LOXL1 gene polymorphisms in exfoliation syndrome and exfoliation glaucoma," Molecular Vision, vol. 14, pp. 533-541, 2008.

[14] V. L. Ramprasad, R. George, N. Soumittra, F. Sharmila, L. Vijaya, and G. Kumaramanickavel, "Association of non-synonymous single nucleotide polymorphisms in the LOXL1 gene with pseudoexfoliation syndrome in India," Molecular Vision, vol. 14, pp. 318-322, 2008.

[15] M. Tanito, M. Minami, M. Akahori et al., "LOXL1 variants in elderly Japanese patients with exfoliation syndrome/glaucoma, primary open-angle glaucoma, normal tension glaucoma, and cataract," Molecular Vision, vol. 14, pp. 1898-1905, 2008.

[16] G. Malukiewicz, H. Lesiewska-Junk, K. Linkowska, M. Mielnik, T. Grzybowski, and N. Sulima, "Analysis of LOXL1 single nucleotide polymorphisms in Polish population with pseudoexfoliation syndrome," Acta Ophthalmologica, vol. 89, no. 1, pp. e64-e66, 2011.

[17] L. Bojić, R. Ermacora, S. Polić et al., "Pseudoexfoliation syndrome and asymptomatic myocardial dysfunction," Graefe's Archive for Clinical and Experimental Ophthalmology, vol. 243, no. 5, pp. 446-449, 2005.

[18] M. Citirik, G. Acaroglu, C. Batman, L. Yildiran, and O. Zilelioglu, "A possible link between the pseudoexfoliation syndrome and coronary artery disease," Eye, vol. 21, no. 1, pp. 11$15,2007$.

[19] G. K. Andrikopoulos, E. K. Mela, C. D. Georgakopoulos et al., "Pseudoexfoliation syndrome prevalence in Greek patients with cataract and its association to glaucoma and coronary artery disease," Eye, vol. 23, no. 2, pp. 442-447, 2009.

[20] R. R. Allingham, M. Loftsdottir, M. S. Gortfredsdottir et al., "Pseudoexfoliation syndrome in Icelandic families," British Journal of Ophthalmology, vol. 85, no. 6, pp. 702-707, 2001.

[21] V. J. Dzau, "Tissue angiotensin and pathobiology of vascular disease a unifying hypothesis," Hypertension, vol. 37, no. 4, pp. 1047-1052, 2001.

[22] Y. Shoenfeld, R. Gerli, A. Doria et al., "Accelerated atherosclerosis in autoimmune rheumatic diseases," Circulation, vol. 112, no. 21, pp. 3337-3347, 2005.

[23] A. de La Sierra and M. Larrousse, "Endothelial dysfunction is associated with increased levels of biomarkers in essential hypertension," Journal of Human Hypertension, vol. 24, no. 6, pp. 373-379, 2010.

[24] F. Cambronero, J. A. Vilchez, A. García-Honrubia et al., "Plasma levels of Von Willebrand factor are increased in patients with hypertrophic cardiomyopathy," Thrombosis Research, vol. 126, no. 1, pp. e46-e50, 2010.

[25] J. Davignon and P. Ganz, "Role of endothelial dysfunction in atherosclerosis," Circulation, vol. 109, no. 23, pp. III27-III32, 2004.

[26] A. Olewicz-Gawlik, A. Danczak-Pazdrowska, K. Klama et al., "Blood serum levels of amino-terminal pro-c-type natriuretic peptide in patients with systemic sclerosis," Connective Tissue Research, vol. 51, no. 2, pp. 83-87, 2010.

[27] U. Güray, A. R. Erbay, Y. Güray et al., "Levels of soluble adhesion molecules in various clinical presentations of coronary atherosclerosis," International Journal of Cardiology, vol. 96, no. 2, pp. 235-240, 2004.

[28] J. Brajkovic, I. Kalauz-Surac, A. Ergegovic, A. Miletic-Juric, N. Susic, and Z. Buric, "Ocular pseudoexfoliation syndrome and internal systemic diseases," Acta Clinica Croatica, vol. 46, supplement 1, pp. 57-61, 2007. 
[29] A. Tarkkanen, A. Reunanen, and T. Kivelä, "Frequency of systemic vascular diseases in patients with primary open-angle glaucoma and exfoliation glaucoma," Acta Ophthalmologica, vol. 86, no. 6, pp. 598-602, 2008.

[30] K. R. Shrum, M. G. Hattenhauer, and D. Hodge, "Cardiovascular and cerebrovascular mortality associated with ocular pseudoexfoliation," American Journal of Ophthalmology, vol. 129, no. 1, pp. 83-86, 2000.

[31] A. Tarkkanen, "Is exfoliation syndrome a sign of systemic vascular disease?” Acta Ophthalmologica, vol. 86, no. 8, pp. 832836, 2008. 


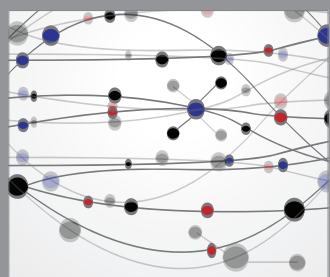

The Scientific World Journal
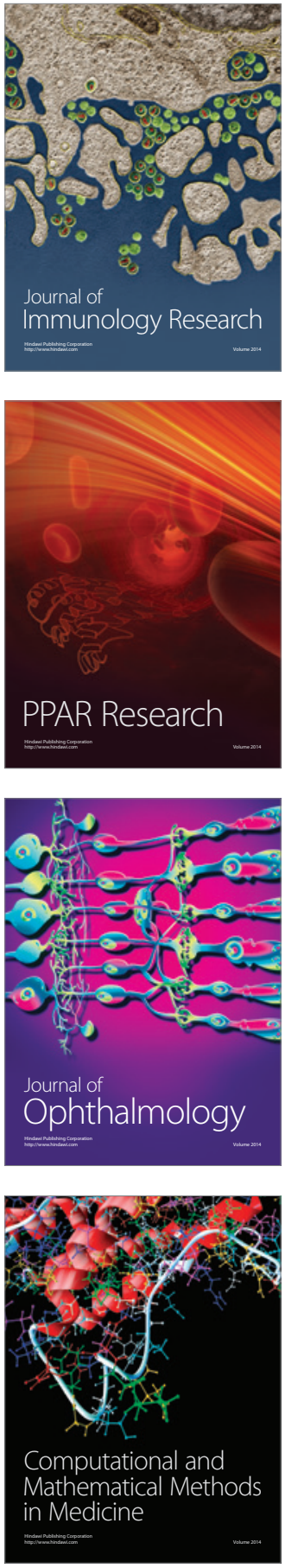

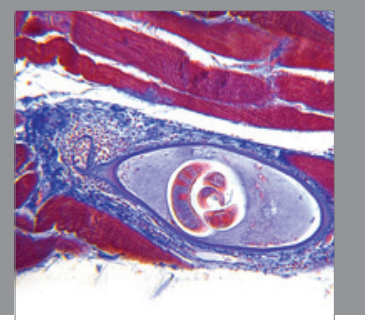

Gastroenterology

Research and Practice
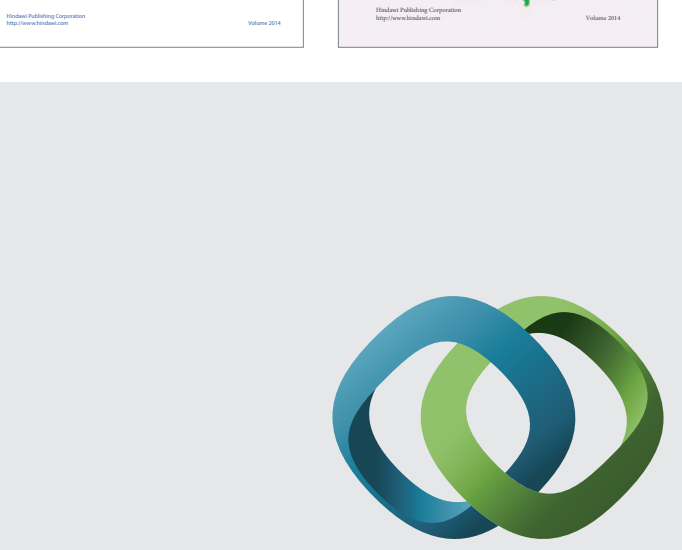

\section{Hindawi}

Submit your manuscripts at

http://www.hindawi.com
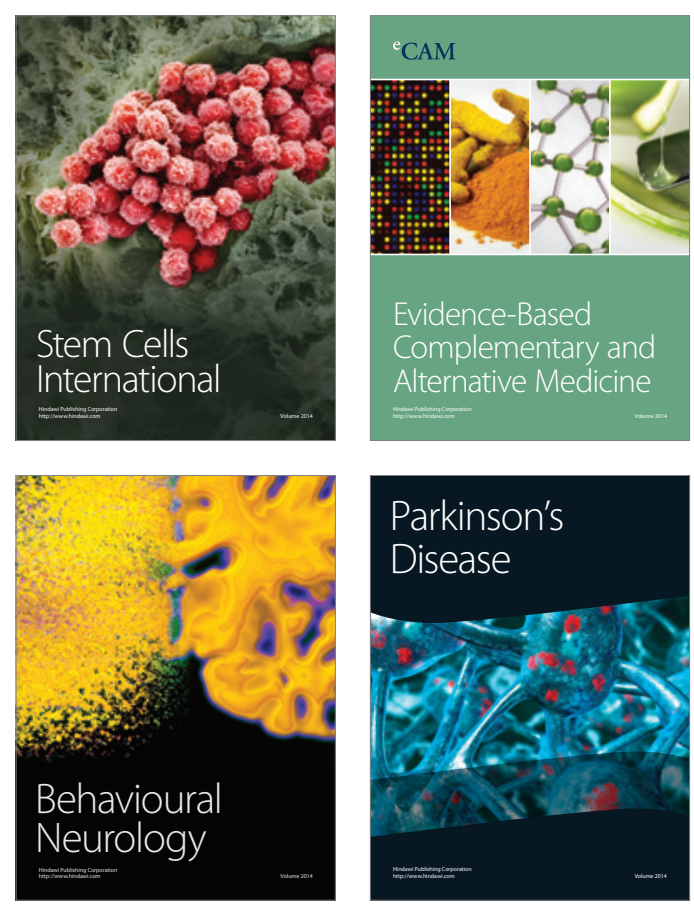

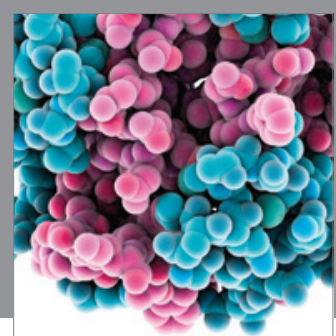

Journal of
Diabetes Research

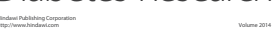

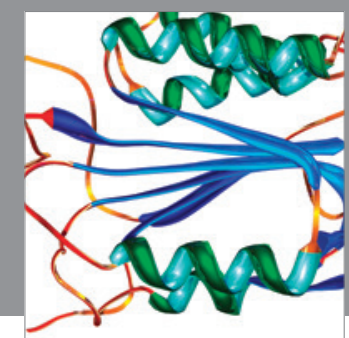

Disease Markers
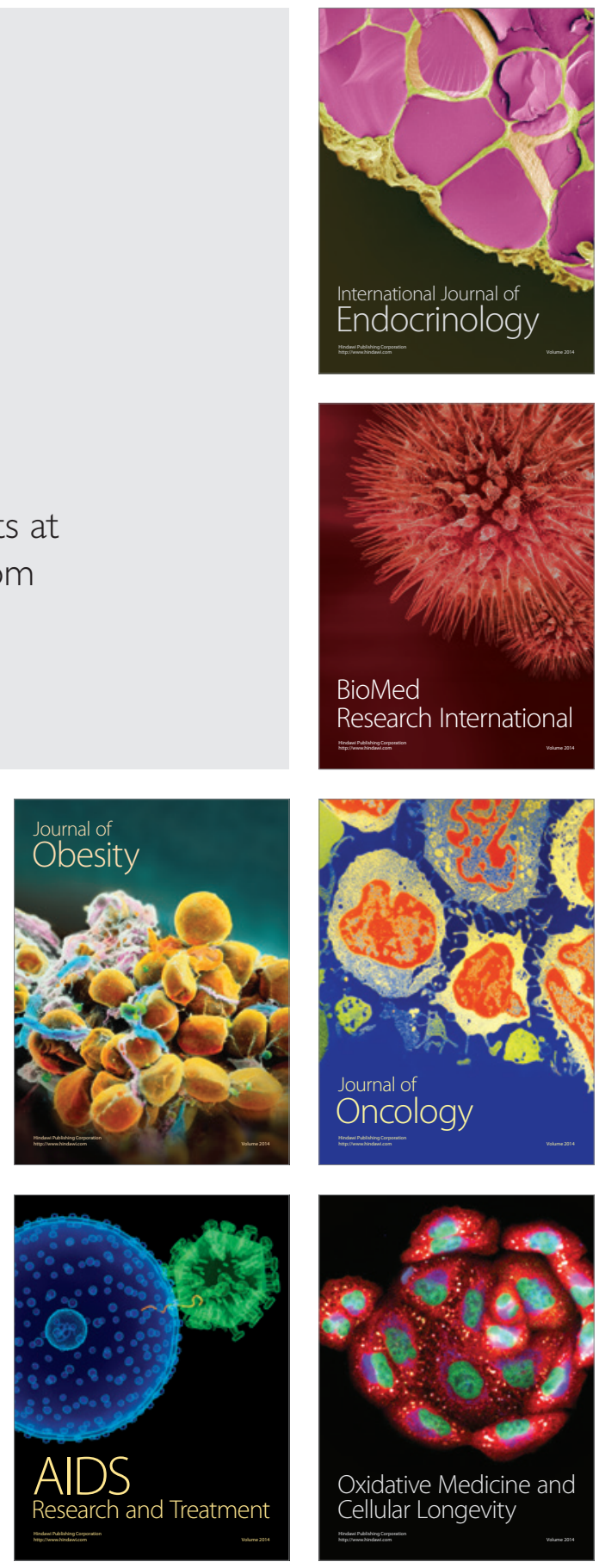